\title{
Emetine Hydrochloride and Dehydroemetine Combined with Chloroquine in the Treatment of Children with Amoebic Liver Abscess
}

\author{
J. N. SCRAGG and S. J. POWELL* \\ From the Departments of Paediatrics and Child Health, and Medicine, University of Natal, \\ and the Amoebiasis Research Unit †, Durban, South Africa
}

A combination of emetine hydrochloride with chloroquine yields better results than either drug alone in the treatment of amoebic liver abscess in adults (Wilmot, Powell, and Adams, 1959). A similar combination of dehydroemetine with chloroquine is equally satisfactory (Wilmot, Powell, MacLeod, and Elsdon-Dew, 1964; Powell, Wilmot, MacLeod, and Elsdon-Dew, 1967). Dehydroemetine is claimed to be less cardiotoxic than emetine (Schwartz and Herrero, 1965), and in adults it produces fewer electrocardiographic changes when given in identical dosage (Powell, 1967) so that up to $2 \mathrm{mg} . / \mathrm{kg}$. day have been given with apparent safety (Powell, Wilmot, MacLeod, and Elsdon-Dew, 1965).

In children, amoebic liver abscess carries a high mortality (Scragg, 1960), but a comparative trial of emetine hydrochloride and chloroquine did not show that cardiac toxicity from emetine was a factor in causing death (Scragg and Powell, 1966). The results suggested that emetine was well tolerated by children and that, as in adults, emetine combined with chloroquine might provide the most effective treatment.

The present trial reports the results of combining either emetine hydrochloride or dehydroemetine with chloroquine in children with amoebic liver abscess.

\section{Material and Methods}

Studies were made on 24 African children, their ages ranging from 1 month to 11 years. The diagnosis of

\footnotetext{
Received June 9, 1967.

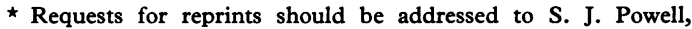
Amoebiasis Research Unit, P.O. Box 1035, Durban, South Africa.

$\dagger$ The Amoebiasis Research Unit is sponsored by the following bodies: The South African Council for Scientific and Industrial Research; The Natal Provincial Administration; The University of Natal; and the United States Public Health Service (Grant AI 01592).
}

amoebic liver abscess was confirmed by the aspiration of characteristic pus from the liver in all patients: in 17 of the 24 aspirates trophozoites of Entamoeba histolytica were identified. In all except one patient, a 7-week-old infant, the amoebic gel-diffusion test was positive.

All patients received chloroquine, $15 \mathrm{mg}$. base $/ \mathrm{kg}$. day, orally for 21 days, and in addition were randomly placed on either emetine hydrochloride, $1 \mathrm{mg} . / \mathrm{kg}$. day, or dehydroemetine, $2 \mathrm{mg} . / \mathrm{kg}$. day, by subcutaneous injection for 10 days. Those with active dysentery also received oral tetracycline to combat intestinal amoebiasis. In 22 patients repeated aspirations of the liver were required, and in 6 surgical drainage of the abscess was eventually necessary, but no additional amoebicides were given.

\section{Results}

The results are summarized in the Table.

Necropsy findings. It will be noted that 3 patients who received emetine combined with chloroquine died. One, a malnourished 16-monthold infant with active dysentery, died 48 hours after beginning treatment; necropsy showed multiple abscesses which had destroyed most of the right lobe of the liver. A second patient, aged 14 months, was critically ill with kwashiorkor and bronchopneumonia and died following surgical drainage on the 24th day; a chronic non-liquefied abscess in the left lobe of the liver was found at

TABLE

Results of Treatment

\begin{tabular}{c|c|c|c|c}
\hline & $\begin{array}{c}\text { No. of } \\
\text { Patients }\end{array}$ & $\begin{array}{c}\text { No. of } \\
\text { Cures }\end{array}$ & $\begin{array}{c}\text { No. of } \\
\text { Deaths }\end{array}$ & $\begin{array}{c}\text { No. of } \\
\text { Relapses }\end{array}$ \\
\hline $\begin{array}{c}\text { Emetine hydro- } \\
\text { chloride. }\end{array}$ & 12 & 9 & 3 & 0 \\
$\begin{array}{c}\text { Dehydroemetine .. } \\
\text { Dehyden }\end{array}$ & 12 & 11 & 1 & 0 \\
\hline
\end{tabular}

Both drugs were given in combination with chloroquine. 
necropsy. The third infant, 1 month old, died on the 9th day; necropsy was refused.

One patient who received dehydroemetine and chloroquine died on the 5 th day. This was an extremely ill 13-month-old infant with profound anaemia and jaundice; at necropsy multiple abscesses in the liver were present, one occupying the whole of the right lobe.

Electrocardiographic findings. Electrocardiograms were obtained before and after completion of treatment in 8 of the group who received emetine and in 11 of those given dehydroemetine. No arrhythmias, conduction defects, or significant tachycardia were observed. However, $\mathrm{T}$ wave inversion developed in 6 children given emetine and in 3 who received dehydroemetine.

Follow-up. Ten children attended for followup from 1 to 8 months after discharge. None had relapsed.

\section{Discussion}

The results of therapy are difficult to assess in children with amoebic liver abscess for several reasons. Even in areas where the disease is frequent in adults it is relatively rare in children, so that large-scale studies are not possible. Moreover, standardization of clinical criteria and management is more difficult than in adults. Age alone is a most important factor in prognosis and can readily affect evaluation of treatment. In this study all 4 deaths occurred among the 13 infants aged 16 months or less, whereas none of the remaining 11 older children died. Regardless of the nature of the therapy, mortality is higher in infants.

Some infants are only brought to hospital when the disease is so far advanced that it is difficult to imagine any form of therapy affecting cure. The necropsy appearances in the two infants who died on the 2nd and 5th days of treatment suggested that the prognosis was hopeless from the outset. A liver abscess of medium size in an adult is relatively enormous in an infant and causes extensive liver destruction. Consequently, the mortality of liver abscess is likely to remain higher in infants despite effective amoebicides.

The place of surgical drainage in management is not well defined. In our present study we tended to resort to it at an earlier stage than previously. Although it was only considered necessary in 6 patients, one of whom suddenly died, earlier surgery may have been a factor in reducing both the death and relapse rates. Premature surgical intervention is undesirable, but in selected instances open drainage has a more important place in the management of children than of adults.

In view of such clinical variations, comparison of the efficacy of drugs must be interpreted with caution. Nevertheless, it appears that either emetine or dehydroemetine can be combined with chloroquine with safety and advantage. Although the immediate case fatality rate may not be significantly influenced by combined therapy, the absence of relapse in our present trial contrasts with our previous experience using single drugs.

For the treatment of adults dehydroemetine is marginally preferred to emetine (Powell et al., 1965). Only long usage will tell if it is more effective in children though we believe that it is. Because it may be slightly more effective and can be given in larger dosage, dehydroemetine is the drug of choice and should be given with chloroquine for the treatment of amoebic liver abscess in children.

\section{Summary}

Emetine hydrochloride combined with chloroquine cured 9 of 12 children with amoebic liver abscess. An alternative combination of dehydroemetine with chloroquine produced cure in 11 of 12 children. No relapses were observed.

Electrocardiographic changes, consisting only of $T$ wave inversion, were noted in 6 who received emetine and in 3 given dehydroemetine.

Although the immediate case fatality rate may not be significantly influenced, a combination of either preparation with chloroquine appears to reduce the relapse rate. Dehydroemetine is preferred to emetine hydrochloride since not only may it be more effective but it is possibly safer even in higher dosage.

We wish to thank Professor H. L. Wallace for advice and access to patients, and Dr. H. Wannenburg, Medical Superintendent, King Edward VIII Hospital, Durban, for facilities.

\section{REFERENCES}

Powell, S. J. (1967). The cardiotoxicity of systemic amebicides: a comparative electrocardiographic study. Amer. F. trop. Med. Hyg., 16, 447.

—, Wilmot, A. J., MacLeod, I. N., and Elsdon-Dew, R. (1965). A comparative trial of dehydroemetine, emetine hydrochloride and chloroquine in the treatment of amoebic liver abscess. Ann. trop. Med. Parasit., 59, 496.

$\longrightarrow,-,-$, and - (1967). A comparative trial of dehydroemetine and emetine hydrochloride in identical dosage in amoebic liver abscess. ibid., $61,26$.

Schwartz, D. E., and Herrero, J. (1965). Comparative pharmacokinetic studies of dehydroemetine and emetine in guinea pigs using spectrofluorometric and radiometric methods. Amer. trop. Med. Hyg., 14, 78. 
Scragg, J. (1960). Amoebic liver abscess in African children. Arch. Dis. Childh., 35, 171.

, and Powell, S. J. (1966). Emetine hydrochloride and chloroquine in the treatment of children with amoebic liver abscess. ibid., 41, 549.

Wilmot, A. J., Powell, S. J., and Adams, E. B. (1959). Chloroquine compared with chloroquine and emetine combined in amebic liver abscess. Amer. F. trop. Med. Hyg., 8, 623.

- - MacLeod, I. N., and Elsdon-Dew, R. (1964). The treatment of amoebic liver abscess with dehydroemetine. Proc. 3rd int. Congr. Chemother., Stuttgart, 1963, 2, 1528. 